$\begin{array}{ll}\begin{array}{l}\text { Australian Journal of } \\ \text { Crop Science }\end{array} & \text { A C S ISSN:1835-2707 } \\ \text { AJCS 15(12) 1442-1445 (2021) } & \text { IST }\end{array}$

doi:

\title{
Research notes
}

\section{Plant growth promoting rhizobacteria enhance the ratoon productivity of} sugarcane

\author{
Chanyarat Paungfoo-Lonhienne ${ }^{1 *}$, Nantida Watanarojanaporn ${ }^{2}$, lan Petersen ${ }^{1}$, Ratchaniwan Jaemsaeng ${ }^{2}$, \\ Peeraya Klomsa-ard ${ }^{2}$, Klanarong Sriroth ${ }^{2}$
}

${ }^{1}$ School of Agriculture and Food Sciences, The University of Queensland, Brisbane, QLD 4072, Australia

${ }^{2}$ Mitr Phol Sugarcane Research Center Co., Ltd., Phu Khiao, Chaiyaphum, 36110, Thailand

*Corresponding author: Chanyarat Paungfoo-Lonhienne

\begin{abstract}
Less than half of the applied chemical fertiliser in intensive cropping systems is utilised by the target crops, with the remaining nutrients contributing to environmental pollution. Reducing the pollution derived from inefficient use of chemical fertilisers has enormous importance for agriculture. Recently, studies have shown that plant growth promoting rhizobacteria (PGPR) Paraburkholderia sp. SOS3 along with a combination of organic and chemical fertilisers, can offer a viable avenue to enhance sugarcane growth while reducing the concentration of chemical fertilisers. Here, we further investigated the effects of adding PGPR with combined organic and chemical fertilisers on sugarcane ratoon productivity (i.e. the second-year ratoon crop). The ratoon crop regenerated from sugarcane fertilised with the chemical-organic fertilisation in the first year, with or without PGPR (4 replicates), was grown in industry-standard practice in the second year. The results show that PGPR inoculation during the initial planting strongly promotes the growth of the ratoon sugarcane in the second year without reapplication of the PGPR. These findings show the high potential of using PGPR along with a combination of organic and chemical fertilisers for improving ratoon crop productivity in sugarcane.
\end{abstract}

Keywords: Fertiliser; Organic Fertiliser; PGPR; Ratoon; Sugarcane

\section{Introduction}

In pursuing higher crop yields, farmers can excessively apply chemical fertilisers without realising the full implications of fertiliser misuse on both their future crops and their local environment. The amount of nitrogen delivered to the soil through fertilisation that is utilised by the crop has been estimated at around $50 \%$, with rates as low as $30-35 \%$ seen in certain areas such as China (Chien et al. 2009). Based on an analysis of numerous studies from around the world, there is evidence that continued application of chemical fertilisers that deposit excess nitrogen in the soil can reduce soil fertility and future crop yields (Mulvaney et al. 2009). In addition, overuse of chemical fertilisers can have significant impacts on surrounding ecosystems and human health. For example, leaching of nitrates into groundwater and waterways can lead to contaminated drinking water (causing cyanosis) and eutrophication (extreme overgrowths of algae leading to the deaths of aquatic organisms) (Aziz et al. 2015). While chemical fertilisation issues are apparent, sole reliance on organic fertilisation might be insufficient to supply the required nutrients without applying a large amount at a significant cost in intensive farming (Delgado et al. 2016).
Recently, plant growth promoting rhizobacteria (PGPR) have been considered as a possible path to this elusive high-yield, high-sustainability cropping system. PGPR naturally thrive in soils where they form symbiotic relationships with host plants. In exchange for certain compounds, the PGPR will provide benefits to the host plant such as nitrogen fixation, phosphate solubilisation, phytohormone production, and defence against phytopathogens (Goswami et al. 2016). One such PGPR, Paraburkholderia sp. strain SOS3 (NCBI ID: 1926494), has recently shown strong results as a fertilisation supplement for the growth of Kikuyu grass (PaungfooLonhienne et al. 2019). In this study, a $50 \%$ organic and $50 \%$ chemical fertilisation regime supplemented with PGPR provided equal yields to $100 \%$ chemical fertilisation. More importantly, this combination also resulted in a $95 \%$ reduction in leached nitrogen compared to the chemical fertiliser only.

A comprehensive field trial was performed in sugarcane cropping (Saccharum officinarum $x$ spontaneum L.) involving this same chemical-organic hybrid fertilisation regime supplemented with PGPR (Paungfoo-Lonhienne et al. 2020). 
This study confirmed the previous findings (PaungfooLonhienne et al. 2019) that the addition of PGPR to a hybrid fertilisation regime could significantly increase crop and sugar yields, with the amount of nitrogen leaching into the soil supposedly reduced.

Here, we aimed to investigate the effect of this fertilisation regime on the ratoon productivity of sugarcane. Ratooning of sugarcane is a practice in which most of the above-ground plant is harvested (i.e. the valuable cane stalk itself), leaving the root system and subterranean buds that can regrow into a fresh crop (Crane and Spreen 1980). Although this practice obviously has some significant benefits from growing multiple crops from a single planting period (both in terms of labour and resources), it has been shown that subsequent ratoon crops will often have decreased sugar yields, and as such, farmers will need to replant the crop after a few years of ratooning to maintain productivity (Raju et al. 2013). We show here that the PGPR SOS3 bacterium applied with a combination of organic and chemical fertilisers has highly beneficial effects on ratoon cane growth and sugar yield.

\section{Results and Discussion}

Sugarcane plants grown for one year (first year of growth) in the presence/absence of PGPR Paraburkholderia sp. SOS3 under a hybrid chemical-organic fertilisation regime (SM (Soil Mate) and $1 / 2$ SM+EcoNPK, see Method) were harvested (Paungfoo-Lonhienne et al. 2020), leaving the root system intact. The remaining truncated plants were then grown for a second year (the ratoon crop) using industry-standard fertilisers without addition of PGPR (See Method). At the end of the second year, the sugarcane stalks were harvested and analysed. The results showed a significant improvement in cane and sugar yields for plants that were treated with PGPR during the first year (Figure 1).

Compared to the SM treatment (treatment 1 and 2, see Method), SM+SOS3 showed a 33\% increase in cane yield $(P<$ $0.001)$ and a $46 \%$ increase in sugar yield $(P<0.0001)$. In the $1 / 2 \mathrm{SM}+$ EcoNPK treatment (treatments 3 and 4 , see Method), the improvements in cane and sugar yields are more modest, with increases of $12 \%$ and $13 \%$, respectively $(P>0.05)$. The stalk thickness and \%Brix are similar in all treatments regardless of the presence or absence of SOS3. Thus, the improvement of cane and sugar yields in SOS3treated plants appears to be mainly due to an increase of the tiller number $(20 \%(P<0.01)$ and $11 \%(P<0.05)$ in SM and $1 / 2 \mathrm{SM}+$ Eco treatments, respectively), and in the SM treatment only, to an increase of the sugarcane height $(14 \%$ increase $(P<0.0001)$, Figure 1$)$.

The overall greater benefits to the ratoon crop of $\mathrm{SM}+\mathrm{SOS} 3$ treatment compared with the $1 / 2 \mathrm{SM}+\mathrm{ECO}+\mathrm{SOS} 3$ treatment is likely related to the composition of SM. SM consists of a combination of chemical and organic fertiliser. The organic part of SM contains at least $55 \%$ of mill mud (material remaining after cane juice is clarified and filtered, containing organic materials in the form of sugars, fibres, and other organic nutrients) in its composition. $1 / 2 \mathrm{SM}+$ Eco contains half the concentration of SM, thus, it can be assumed that mill mud contains some chemical or biological components preferred by the PGPR SOS3 bacterium over EcoNPK.

The results from this study support the previous research (Paungfoo-Lonhienne et al. 2020) showing that the chemicalorganic hybrid fertilisation regime in combination with PGPR SOS3 is highly beneficial for sugarcane growth and associated sugar yield.
However, the effect of the addition of PGPR SOS3 to the plant crop is more pronounced in its ratoon crop. Indeed, in the $\mathrm{SM}+\mathrm{SOS} 3$ treatment, the increase of sugar yield is approximately 4 -fold greater in the ratoon crop (46\%, second year), compared to the plant crop (12\%, first year, Paungfoo-Lonhienne et al. 2020).

\section{Materials and Methods}

Field experiments were conducted at Mitr Phol Sugarcane Research Center, Thailand during April 2019-January 2021 in two seasons. In the first-year plant crop (PaungfooLonhienne et al. 2020), four treatments were applied to the plant cane (starting from sugarcane setts) of commercial variety KK3:

1 Soil Mate (MitrPhol Sugar Corporation, Thailand) consisting of a combination (1:2 weight ratio) of chemical fertiliser $(16 \% \mathrm{~N}, 16 \% \mathrm{P}, 8 \% \mathrm{~K})$ and organic fertiliser $(1 \% \mathrm{~N}$, $2 \% \mathrm{P}, 2 \% \mathrm{~K})-\mathrm{SM}$

2 Soil Mate supplemented with PGPR SOS3 bacterium (NCBI ID: 1926494; Sustainable Organic Solutions Pty Ltd., Brisbane, Australia) - SM+SOS3

$3 \quad 1: 1$ ( $N$ basis) Soil Mate and EcoNPK (poultry manure-based fertilisers containing $4 \% \mathrm{~N}, 3 \% \mathrm{P}, 3 \% \mathrm{~K}$, Sustainable Organic Solutions Pty Ltd., Brisbane, Australia) $1 / 2 \mathrm{SM}+\mathrm{ECO}$

$4 \quad 1: 1$ ( $N$ basis) Soil Mate and EcoNPK supplemented with PGPR SOS3 bacterium $-1 / 2 \mathrm{SM}+\mathrm{EcO}+\mathrm{SOS} 3$

All treatments were fertilised to achieve $57 \mathrm{~kg} \mathrm{~N}$ per hectare, with or without the addition of $15 \mathrm{~kg}$ of SOS3 PGPR product $\left(10^{7}\right.$ cell. $\left.\mathrm{g}^{-1}\right)$, for nine months. The plot size was $6,400 \mathrm{~m}^{2}$ (Paungfoo-Lonhienne et al. 2020). The ratoons of these plants were then grown with industry-standard practice (combination of Soil Mate chemical and organic fertilisers at 1:2 weight ratio) without the addition of PGPR for the second year. The fertilisers were applied into the open row shoulders twice; 1 week and 4 months after the first year harvest (Figure 2). After 12 months of growth (January 2020 - January 2021) sugarcane was analysed for heigh, thickness, number of tillers, cane yield, \%Brix (using Atago Portable Brix Refractometer, Japan), and commercial cane sugar yield (CCS, using ICUMSA Method GS5/7-1). The sampling plots consisting of six rows of sugarcane $(10 \mathrm{~m}$ long, $1.85 \mathrm{~m}$ row spacing) and four replicated plots per treatment. Statistical analyses of the significant differences between PGPR and no PGPR amendment within the same fertiliser type were performed using Student's t test (GraphPad Prism 8, GraphPad Software, Inc.).

\section{Conclusion}

This study demonstrated that the application of PGPR SOS3 in a hybrid chemical-organic fertilising system at the first year of sugarcane planting improves the plant and sugar yields of its first ratoon crop. This system has the potential for overcoming the decline in cane yield in successive ratoons, which is a current problem in sugarcane cultivation. If the addition of PGPR to soils can maintain ratoon productivity for years without replanting, this would represent a significant improvement for the industry. However, continuing long-term studies is required to assess this beneficial effect on the following growing seasons. 

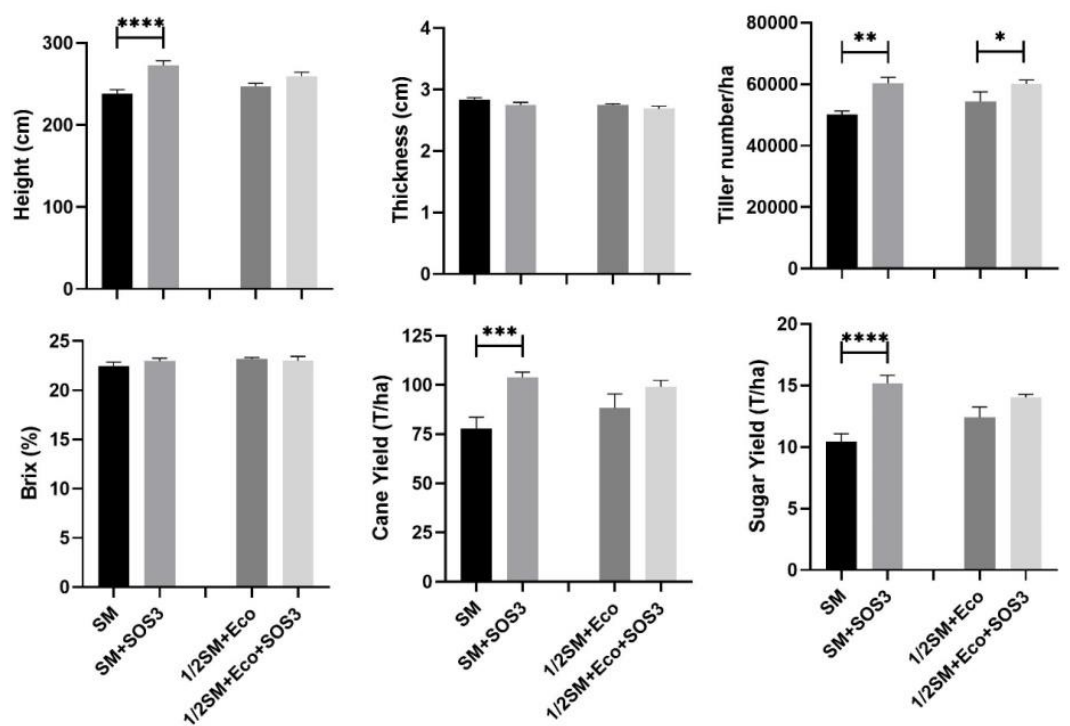

Fig 1. Data collected for the first ratoon (second year) of plant sugarcane grown the first year under various fertilisation regimes, with or without supplemented PGPR. Error bars represent the standard error from the mean. Statistical significance was assessed using a Student's $t$ test between treatments supplemented with PGPR and their respective controls: $P<0.05 ;{ }^{* *}, P<0.01 ;{ }^{* * *}$, $P<0.001 ; * * *, P<0.0001$

A

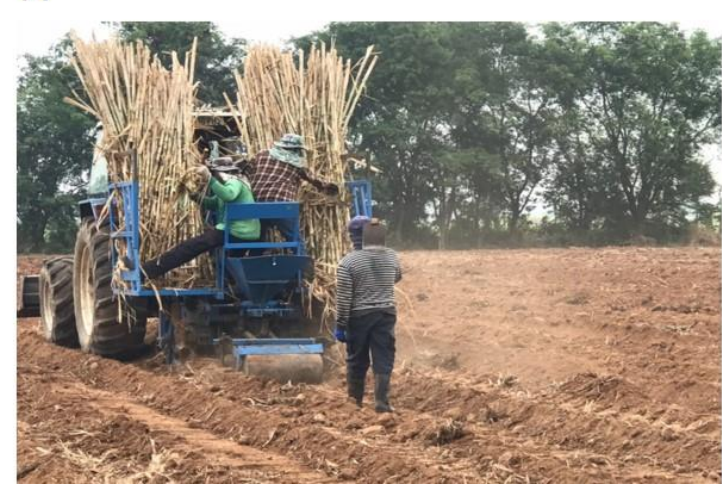

B

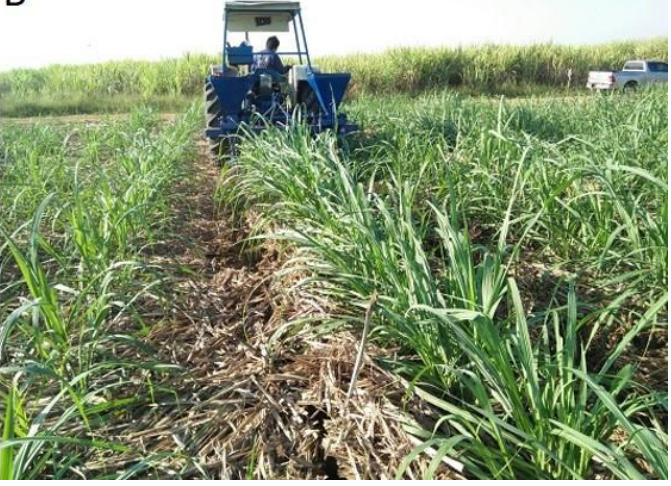

Fig 2. Sugarcane field trials at planting and fertilising performed at Mitr Phol Sugarcane Research Center, Thailand, over two consecutive years. The first year plant cane was started from cane setts, with fertilisers and PGPR SOS3 bacterium applied on the setts (A, Paungfoo-Lonhienne et al., 2020). The second year crop (ratoon crop) was regenerated from the stumps of the harvested first year crop (B), and the current industry-standard practice was applied (Soil Mate fertilisers without PGPR were placed into the open row shoulders).

\section{Acknowledgements}

We would like to thank $\mathrm{Mr}$ Witoon Boonkerd and $\mathrm{Mr}$ Anuwat Janlae for assistance with growing and maintaining plants in the field. This research was funded by Cooperative Research Centres Projects Grant CRCPFIVE000015.

\section{Conflicts of Interest}

The authors declare that they have no known competing financial interests or personal relationships that could have appeared to influence the work reported in this paper.

\section{References}

Aziz T, Maqsood MA, Kanwal S, Hussain S, Ahmad HR, Sabir $M$ (2015) Fertilizers and Environment: Issues and Challenges. In: Hakeem KR (ed) Crop Production and Global Environmental Issues. Springer International Publishing, Cham. 575-598.
Chien SH, Prochnow LI, Cantarella H (2009) Recent Developments of Fertilizer Production and Use to Improve Nutrient Efficiency and Minimize Environmental Impacts. In: Advances in Agronomy, vol 102. Academic Press. 267322.

Crane DR, Spreen TH (1980) A Model of the Stubble Replacement Decision for Florida Sugarcane Growers. JAAE. 12(2):55-64.

Delgado A, Quemada M, Villalobos FJ (2016) Fertilizers. In: Villalobos FJ, Fereres E (eds) Principles of Agronomy for Sustainable Agriculture. Springer International Publishing, Cham. 321-339.

Goswami D, Thakker JN, Dhandhukia PC (2016) Portraying mechanics of plant growth promoting rhizobacteria (PGPR): A review. Cogent Food Agric. 2(1):1127500.

International Commission for Uniform Methods of Sugar Analysis (ICUMSA) Methods book (2011). The 
Determination of Pol (Polarisation), Brix and Fibre in Cane and Bagasse by the Wet Disintegrator Method with Lead Subacetate. Method GS5/7-1.

Mulvaney RL, Khan SA, Ellsworth TR (2009) Synthetic Nitrogen Fertilizers Deplete Soil Nitrogen: A Global Dilemma for Sustainable Cereal Production. J Environ Qual. 38(6):2295-2314.

Paungfoo-Lonhienne C, Redding M, Pratt C, Wang W (2019)

Plant growth promoting rhizobacteria increase the efficiency of fertilisers while reducing nitrogen loss. J Environ Manag. 233:337-341.

Paungfoo-Lonhienne C, Watanarojanaporn N, Jaemsaeng $\mathrm{R}$ (2020) Plant growth promoting rhizobacteria enhance the efficiency of the combination of organic and chemical fertilisers in sugarcane. OJE. 10:440-444.

Raju G, Polur Nagaraja Gururaja R, Palaniappan R, Babu Poojary S, Srinivasan S (2013) Physiological Studies on Ratoonability of Sugarcane Varieties under Tropical Indian Condition. Am J Plant Sci. 4:274-281. 